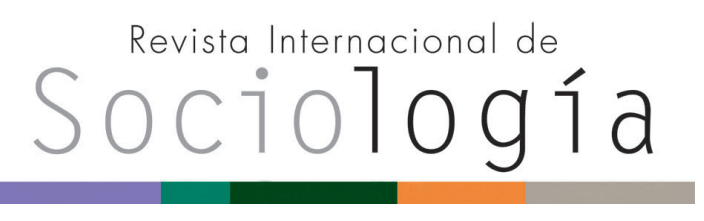

Revista Internacional de Sociología RIS

vol. 78 (1), e149, enero-marzo, 2020, ISSN-L:0034-9712 https://doi.org/10.3989/ris.2020.78.1.18.037

\section{LA CENTRALIDAD DE LOS CRITERIOS DE MERECIMIENTO EN LA EXPLICACIÓN DE LAS ACTITUDES HACIA LA CONDICIONALIDAD DE LA POLÍTICA SOCIAL}

\author{
Xavier Guijarro Rubinat \\ Universidad Autónoma de Barcelona \\ xavier.guijarro@gmail.com \\ ORCID iD: https://orcid.org/0000-0001-5820-942X
}

Cómo citar este artículo / Citation: Guijarro Rubinat, X. 2020. "La centralidad de los criterios de merecimiento en la explicación de las actitudes hacia la condicionalidad de la política social". Revista Internacional de Sociología 78(1): e149. https://doi.org/10.3989/ ris.2020.78.1.18.037

\begin{abstract}
Resumen
Las políticas de activación laboral y el paradigma de la inversión social han promovido el debate acerca de la evolución de los estados de bienestar hacia una mayor condicionalidad de la política social. Este estudio explora el papel de los criterios de merecimiento y sus interacciones con el autointerés y la ideología para entender cómo las personas desarrollan actitudes específicas hacia la condicionalidad de la política social. Las conclusiones se extraen a través del análisis de la literatura y de una encuesta de opinión pública en Cataluña que presenta una oportunidad única para desarrollar una estrategia empírica fundamentada en la distinción teórica entre criterios de merecimiento y condicionalidad de la política social. El análisis evidencia el poder explicativo de los criterios de merecimiento y cómo estos interfieren con el autointerés y la ideología. Los hallazgos son específicamente relevantes para la comunicación política.
\end{abstract}

\section{Palabras Clave}

Actitudes hacia el bienestar; Estado de bienestar; Homo reciprocans; Percepción de merecimiento; Políticas de activación laboral.

\section{THE CENTRALITY OF \\ DESERVINGNESS CRITERIA IN EXPLAINING ATTITUDES TOWARDS SOCIAL POLICY CONDITIONALITY}

Copyright: @ 2020 CSIC. Este es un artículo de acceso abierto distribuido bajo los términos de la licencia de uso y distribución Creative Commons Reconocimiento 4.0 Internacional (CC BY 4.0).

Recibido: 26/02/2018. Aceptado: 16/06/19

Publicado online: 16/03/2020

\begin{abstract}
Active labour market policies and social investment paradigm have promoted debates on the evolution of welfare states towards a greater social policy conditionality. This study explores the role of deservingness criteria and their interaction with self-interest and ideology to understand how people develop specific attitudes towards social policy conditionality. Conclusions are drawn through the analysis of existing literature and a public opinion survey from Catalonia that brings a unique opportunity to build an empirical strategy based on the theoretical distinction between deservingness criteria and social policy conditionality. The analysis demonstrates the explanatory power of deservingness criteria and how these interfere with selfinterest and ideology. Findings are especially relevant for political communication.
\end{abstract}

\section{KeYWoRdS}

Active labor market policies; Deservingness perception; Homo reciprocans; Welfare attitudes; Welfare states. 


\section{INTRODUCCIÓN}

Este artículo se inserta en la línea de investigación sobre actitudes hacia el estado de bienestar (en adelante, EB). A raíz del trabajo iniciado por EspingAndersen (1990), quien explora los distintos regímenes de bienestar, nace el interés por investigar el distinto apoyo que recibe cada EB y cuáles son los determinantes de este apoyo. El trabajo de Svallfors (1997) analizando las actitudes hacia la redistribución de los EB es un buen exponente de esta línea de investigación. Con el tiempo, esta línea ha ido consolidándose, ampliando la mirada hacia los determinantes individuales (Roosma 2016; Reeskens y van Oorschot 2015; Calzada et al. 2014; Kulin y Svallfors 2013; Stegmueller et al. 2012; Jæger 2006, 2009; Linos y West 2003; Andreß y Heien 2001; Chong, Citrin y Conley 2001). Los determinantes individuales principales que se han identificado tienen que ver con la posición estructural (el nivel de interés objetivo hacia el EB o un determinado programa) y la ideología (el grado en que coinciden los valores políticos propios con los valores que inspiran el EB o un determinado programa).

En este contexto, el artículo se pregunta acerca de la centralidad de los criterios de merecimiento en la explicación de las actitudes hacia la condicionalidad de la política social, de manera que persigue dos grandes objetivos generales:

1. Fundamentar teóricamente los criterios de merecimiento y demostrar su impacto en la configuración de actitudes hacia el EB. Grosso modo, los criterios de merecimiento se refieren a las reglas según las cuales las personas identifican a otras como merecedoras de recibir ayuda (van Oorschot 1998). Son, por tanto, reglas que regulan la cooperación.

2. Defender la relevancia actual de estudiar específicamente las actitudes hacia la condicionalidad de la política social (hacia las condiciones legales para ser beneficiario de una prestación social) en el contexto del giro hacia las políticas de activación laboral e inversión social (González Begega y Del Pino 2017; Wright 2016; Leoni 2015; Moreno y Serrano-Pascual 2007).

Para dar respuesta a los objetivos generales se marcan cuatro objetivos específicos:

1. Elaborar un esquema de los criterios de merecimiento originales más sintético, considerando bajo la misma categoría todos los que se basan en una valoración de la conducta.

2. Defender la necesidad teórica y metodológica de distinguir entre merecimiento y condicionalidad como dos dimensiones analíticamente separadas.

3. Contrastar la importancia explicativa de los criterios de merecimiento en relación con las actitudes hacia la condicionalidad de la política social.
4. Explorar cómo se relacionan los criterios de merecimiento con el autointerés y la ideología.

Se empieza describiendo qué es la condicionalidad de la política social desde el enfoque analítico de Clasen y Clegg (2007) para establecer las actitudes objeto de estudio. A continuación, se presentan las dimensiones teóricas tradicionales de autointerés e ideología y sus implicaciones en relación con las actitudes hacia la condicionalidad. Llegados a este punto, se fundamenta el esquema de los criterios de merecimiento y su potencial explicativo, apuntando diversas implicaciones y las consideraciones teóricas y metodológicas que distinguen merecimiento y condicionalidad.

Esta distinción implica una estrategia empírica novedosa para profundizar en el campo del merecimiento, contribuyendo a paliar la falta de datos y estudios que destacan van Oorschot y Roosma (2015). La contrastación empírica se realiza con datos demoscópicos relativos a la población de Cataluña para el año 2010, utilizando la técnica de sistemas de ecuaciones estructurales que sirve para el doble objetivo de explorar la interacción de los criterios de merecimiento con las otras dimensiones y cuantificar su peso explicativo. Es necesario recalcar que esta aproximación difiere de forma importante a la utilizada en los estudios sobre la legitimidad social del EB y los programas dirigidos a distintos colectivos (Calzada y Del Pino 2016; Roosma 2016).

Los resultados muestran el acierto de diferenciar los criterios de merecimiento de la condicionalidad de la política social, confirman el poder explicativo de los primeros y contribuyen a entender mejor la interacción entre las distintas dimensiones explicativas. La consideración de un marco teórico más amplio con centralidad de los criterios de merecimiento, además, ofrece claves para pensar sobre el diseño de la política social y la comunicación política.

\section{Marco teóRICo}

\section{Conceptualización de las actitudes hacia la condicionalidad de la política social}

La condicionalidad de la política social como objeto de estudio ha ganado interés desde la presentación del enfoque de las condicionalidades de Clasen y Clegg (2007). El esquema sirve para identificar cambios de tipo cualitativo en el seno de los EB: sin observarse cambios superficiales a nivel cuantitativo (de gasto social), las condiciones para ser beneficiarios pueden cambiar (endureciéndose o suavizándose). Por tanto, implica mover el foco desde el nivel redistributivo hacia el tipo de condicionalidades, observando un nivel más profundo y cualitativo. He ahí su interés y su potencial. 
Para estudiar estos cambios, identifican una tipología de tres condiciones de las políticas sociales: categoría, circunstancia y conducta. Las condiciones de categoría se refieren a la pertenencia de un individuo a una categoría de apoyo legalmente definida. Por ejemplo, las condiciones para ser considerado jubilado, desempleado o ciudadano nacional. Las categorías pueden ser redefinidas con parámetros más amplios o más estrechos (por ejemplo, retrasando o adelantando la edad de jubilación). En segundo lugar, aparecen las condiciones de circunstancia, que se refieren al nivel de protección al que tiene acceso el individuo según sus contribuciones pasadas o su situación económica. En último lugar, aparecen las condiciones de conducta, referidas a las obligaciones de los individuos para mantener su condición de beneficiarios.

El enfoque toma especial relevancia en el contexto del debate acerca de si en Europa se está produciendo un giro hacia las políticas de activación laboral e inversión social por parte de los EB. Como apunta Bonoli (2010), las políticas de activación pueden tomar distintas formas, pero el interés actual se basa en el énfasis especial en las condiciones de conducta de los beneficiarios y el apoyo a su empleabilidad. Este acento conlleva una transformación de la distribución de derechos y obligaciones de la acción protectora tradicional de los EB, bajo la idea de que los derechos conllevan deberes (Moreno y Serrano-Pascual 2007). Específicamente, el cambio se materializa con medidas que promueven el empleo como mecanismo de provisión de bienestar social (workfare) a partir del control y las sanciones a los beneficiarios, la limitación de la cobertura, la reducción de las cuantías y la introducción de planes individualizados que hacen la relación contractual (Fletcher y Wright 2018).

\section{Predicciones desde las dimensiones tradi- cionales de autointerés e ideología}

Para explicar las actitudes hacia la condicionalidad, el punto de partida de esta investigación son las dos grandes dimensiones explicativas ofrecidas por la literatura: el autointerés, que identifica el modelo antropológico del homo economicus, y la ideología, que refiere un homo sociologicus.

Considerando el autointerés, la literatura destaca el distinto interés que desarrollan los individuos según su posición estructural. El autointerés procede del cálculo racional de las posibilidades de ser beneficiario de uno o varios programas de los programas del EB (de la utilidad esperada). A modo ilustrativo, habitualmente se destacan como factores relevantes la edad, el sexo, el nivel de estudios o de ingresos y constructos como el estatus o la clase social. Desde la mirada del homo economicus, los ubicados en las posiciones estructurales más vulnerables desarrollarán actitudes menos condicionales. Si bien esta es la hipóte- sis principal, Jeene, van Oorschot y Uunk (2013) han propuesto la llamada "hipótesis de la competitividad por los recursos". Con ella se pretende explicar el hecho de que algunos individuos más autointeresados muestren actitudes que, a priori, van contra su propio interés. Esto implica que muestren actitudes más condicionales con tal de maximizar sus oportunidades: les interesa mantener limitado el alcance de las prestaciones para reducir las posibilidades de verse desplazados como (potenciales) beneficiarios.

Por otro lado, la investigación ha mostrado que, si la ideología de un individuo coincide con los valores políticos que inspiran el EB o uno de sus programas, entonces mostrará más apoyo al EB. Si bien es habitual utilizar la autoubicación en el eje izquierda-derecha, huelga decir que su naturaleza multidimensional plantea la necesidad de captar mejor los factores implicados (Weber y Federico 2013). En este sentido, el grado de igualitarismo es uno de los indicadores más pertinentes, mostrando una significatividad recurrente en distintos contextos nacionales (Calzada et al. 2014). Desde la mirada del homo sociologicus, las actitudes hacia la condicionalidad serán una expresión de la ideología de los individuos. Así, los individuos a la izquierda del eje ideológico y los más igualitaristas desarrollaran actitudes menos condicionales, basándose en la creencia sobre la responsabilidad redistributiva del Estado y la solidaridad.

\section{Potencial explicativo de los criterios de me- recimiento: fundamentación e implicaciones de la propuesta}

Los criterios de merecimiento son reglas sencillas que utilizan las personas para juzgar el merecimiento de un individuo o de una categoría social. El cumplimiento de estas reglas genera la percepción de merecimiento que, asociada a la predisposición para cooperar o ayudar, se traduce en actitudes más o menos condicionales. Es importante detectar que no solo puede ser relevante la percepción sobre un caso o colectivo determinado, sino el uso, valor o importancia que se les da a los criterios per se.

Los criterios identificados inicialmente por van Oorschot $(1998,2000)$ son los de control, necesidad, identidad, actitud y reciprocidad. Antes de nada, es interesante detectar que control, actitud y reciprocidad hacen referencia a la conducta del individuo, lo que permite pensar en una versión más sintética del esquema original. De hecho, dentro de un criterio más genérico de conducta se podrían ubicar otros criterios muy cercanos conceptualmente como los de responsabilidad, intencionalidad o esfuerzo estudiados por otros autores (Petersen et al. 2012; Gaeta 2012; Feather 2006; Cosmides y Tooby 2006; Linos y West 2003).

El argumento a favor de esta concepción proviene de la investigación de Feather (2006). Este revela que, en los juicios de merecimiento según conducta, opera 
una mecánica básica: la relación entre una conducta con el resultado u objetivo que le prosigue. Si hay una coherencia lógica entre conducta y resultado, entonces se percibe merecimiento. Por tanto, lo relevante está en la mecánica común que subyace a la evaluación de la conducta, transversal a los distintos criterios citados.

Además, es posible identificar una motivación prosocial común a la valoración de la conducta: la reciprocidad. La importancia de esta motivación prosocial en el ámbito del EB ha sido especialmente destacada (Stiefken 2014; León 2012; Moreno y Serrano-Pascual 2007), dando lugar a la defensa del modelo antropológico de homo reciprocans (Bowles y Gintis 2000). De hecho, los criterios de merecimiento, tal como la idea del homo reciprocans y las motivaciones prosociales (Noguera et al. 2011), tienen que ver con las reglas que regulan la cooperación: aparte de la reciprocidad asociada al criterio de conducta, la investigación ha detectado la relevancia de la solidaridad (Delton et al. 2018) y el altruismo intragrupal (Reeskens y van Oorschot 2012; Yamagishi et al. 2008), que se pueden asociar al criterio de necesidad e identidad respectivamente.

Las consideraciones anteriores permiten respaldar un esquema más sintético de los criterios de merecimiento, respaldado en las motivaciones prosociales (Cuadro 1).

Como se puede observar, el hecho de que los criterios de merecimiento impliquen reglas que regulan la cooperación proporciona una mirada más amplia, caracterizada por su carácter normativo y moral (relativo a quién ayudar y por qué). En este sentido, es posible integrar los criterios de merecimiento en la perspectiva de la economía moral del EB (TaylorGooby et al. 2018; Mau 2003; Arts y Gelissen 2001).
Considerando los resultados de esta perspectiva, así como los de Jeene, van Oorschot, y Uunk (2013) acerca de cómo distintos grupos sociales usan distintos criterios, es razonable pensar que los criterios de merecimiento interaccionan con los efectos de la ideología y del autointerés desde su carácter moral.

Por el lado de la ideología, los juicios de merecimiento según conducta pueden fundamentar el efecto del igualitarismo y la ética del trabajo (responsabilidad pública o individual, valor del esfuerzo) y los juicios según necesidad, el efecto del universalismo (cobertura selectiva o universal). Por el lado del autointerés, la posición desde la que un individuo realiza su juicio puede hacerle más o menos propenso a dar valor a la conducta y la necesidad según su propia experiencia de las fuerzas sociales. Además, en ambos casos los criterios de merecimiento aportan una fuente de variabilidad de naturaleza distinta: no solo es posible que fundamenten los efectos del autointerés y la ideología, sino que interfieran con ellos, distorsionando sus predicciones. Es decir, pueden ser transversales a distintos grupos sociales.

De cualquier modo, la concurrencia de distintas dimensiones explicativas de las actitudes hacia la condicionalidad permite pensar en el poder del encuadramiento o framing (priming) discursivo de la política social. Así, con tal de influenciar el proceso de formación de actitudes, el encuadramiento puede primar las bases ideológicas, los beneficios materiales para distintos grupos o los criterios de merecimiento en pugna, haciendo que las personas se inclinen más por una u otra dimensión (Petersen, Slothuus y Togeby 2010; Petersen et al. 2010; Chong y Druckman 2007; Slothuus 2007; Chong, Citrin y Conley 2001).

Cuadro 1.

Resumen y fundamentación de los criterios de merecimiento

\begin{tabular}{|c|c|c|c|}
\hline Criterio & Fuente de merecimiento & Regla & Motivación \\
\hline Necesidad & $\begin{array}{l}\text { Percepción o importancia de las } \\
\text { dificultades sociales y económicas } \\
\text { individuo }\end{array}$ & $\begin{array}{l}\text { Cuánto más necesitado se perciba al } \\
\text { individuo, más merecedor. }\end{array}$ & Solidaridad \\
\hline Identidad & $\begin{array}{l}\text { Percepción o importancia de la } \\
\text { procedencia del individuo (in-group/ } \\
\text { out-group) }\end{array}$ & $\begin{array}{l}\text { Si se percibe como parte del mismo grupo, } \\
\text { más merecedor. }\end{array}$ & Altruismo intragrupal \\
\hline \multirow{6}{*}{ Conducta } & \multirow{6}{*}{$\begin{array}{l}\text { Percepción o importancia de la con- } \\
\text { ducta del individuo }\end{array}$} & Si se percibe reciprocidad, más merecedor. & \multirow{6}{*}{ Reciprocidad fuerte } \\
\hline & & Si se percibe esfuerzo, más merecedor. & \\
\hline & & $\begin{array}{l}\text { Si se percibe responsable de su situación, } \\
\text { menos merecedor. }\end{array}$ & \\
\hline & & $\begin{array}{l}\text { Si se percibe control sobre su situación, } \\
\text { menos merecedor. }\end{array}$ & \\
\hline & & $\begin{array}{l}\text { Si se percibe intencionalidad de engañar } \\
\text { (gorroneo), menos merecedor. }\end{array}$ & \\
\hline & & $\begin{array}{l}\text { Si se percibe más obediente, más } \\
\text { merecedor. }\end{array}$ & \\
\hline
\end{tabular}


Por último, es necesario destacar que el potencial explicativo de los criterios de merecimiento solo tiene sentido considerando, como apunta Conybeare (2007), que las dimensiones del merecimiento y la condicionalidad son analíticamente distintas, siendo la primera causalmente anterior. Hay razones tanto teóricas como metodológicas que lo fundamentan, y atenderlas convierte la estrategia de investigación aquí adoptada en novedosa.

Las investigaciones demoscópicas previas, incluso las más recientes, solapan las dimensiones de merecimiento y condicionalidad (Meuleman et al. 2018; Calzada y Del Pino 2016; van Oorschot y Roosma 2015). Este solapamiento, que puede inducir a equívocos, ocurre al estudiar qué programas del EB son más populares (o a qué categorías debe condicionarse la política social: jubilados, jóvenes, parados, inmigrantes, mujeres...), para deducir de ello la legitimidad social del EB o sus programas. En estos estudios, los criterios de merecimiento son el elemento teórico que permite interpretar el distinto apoyo observado empíricamente, pero no forman parte del aparato estadístico como causas de las supuestas actitudes hacia la condicionalidad. Dada la reciente popularidad de este tipo de estudios, es necesario clarificar el lugar y la naturaleza de cada dimensión y recalcar que, en esta investigación, la estrategia empírica es diferente.

A nivel teórico, una apreciación central para la distinción es que las actitudes hacia la condicionalidad se refieren a un objeto concreto, son de dominio específico. Parafraseando a Feather (2003), las actitudes hacia la condicionalidad se definen en relación con un contexto de referencia externo a la personas, que tiene que ver con normas y principios legales acerca del acceso y mantenimiento de la condición de beneficiario a través de condiciones de categoría, circunstancia y conducta como las descritas anteriormente.

Los criterios de merecimiento, en cambio, son de dominio transversal y, más allá de la política social, existen en otros ámbitos como la justicia criminal (Cosmides y Tooby 2006) o las interacciones sociales que plantean el problema del polizón (Delton et al. 2012). Según la caracterización de Schwartz (2006), los criterios de merecimiento pueden ser entendidos como "valores básicos". Es decir, como valores que atienden a cuestiones que operan más profundamente y son relevantes en distintas dimensiones, mientras las actitudes pueden cambiar mucho más rápido y son de dominio específico. Esta distinción teórica entre valores y actitudes tiene, a su vez, implicaciones metodológicas: como también ha defendido Sundberg (2014), puede conllevar endogeneidad en los modelos, explicando actitudes con actitudes.

De esta forma, entender adecuadamente la naturaleza distinta de cada dimensión, así como las interferencias que pueden producir los juicios de merecimiento respecto de la ideología y el autointerés, puede contribuir a reducir y comprender el grado de desajuste entre datos y teoría existente en los estudios; una cuestión que ha sido objeto de debate por autores como Petersen y Aarøe (2012), Jæger (2008) y Noya (2004).

\section{Metodología}

\section{Hipótesis y modelo de análisis}

Considerando todo lo anterior, en primer lugar se deriva una hipótesis acerca de los criterios de conducta:

- H1: Es posible construir de forma consistente una sola variable que englobe distintos criterios según conducta.

En segundo lugar, en relación con las interacciones:

- H2: Los criterios de merecimiento interfieren en la relación de la ideología y el autointerés con las actitudes hacia la condicionalidad.

En tercer lugar, en relación con el uso de distintos criterios por distintos grupos sociales:

- H3: Para los individuos políticamente a la izquierda e igualitaristas, los criterios de merecimiento según conducta y necesidad no serán relevantes.

- H4: Para los individuos más autointeresados, los criterios de merecimiento según conducta y necesidad no serán relevantes.

Finalmente, en relación con las actitudes hacia la condicionalidad:

- H5: Los individuos políticamente a la izquierda e igualitaristas desarrollarán actitudes menos condicionales.

- H6: Los individuos más autointeresados desarrollarán actitudes menos condicionales.

- H7: Los individuos que más usen los criterios de merecimiento según necesidad o conducta desarrollarán actitudes más condicionales.

- H8: Los criterios de merecimiento tienen un peso explicativo central.

Considerando la hipótesis relativa a las interacciones entre las dimensiones explicativas ( $\mathrm{H} 2)$, se pueden plantear tres modelos de vías (figura 1):

- En primera instancia se considera el modelo A, que sirve de base y toma la forma de los modelos habituales de regresión múltiple, sin vías.

- A continuación se plantea el modelo $B$, en el que sí existen vías: las dimensiones tradicionales de autointerés e ideología solo tienen un efecto indirecto en las actitudes hacia la condicionalidad a través de los criterios de merecimiento. En este modelo se obtiene una mirada a partir del hecho de que distintos grupos sociales usan distintos 
criterios de merecimiento. Además, permite evaluar si, a través de estos, se pueden interpretar la ideología y el autointerés.

- Finalmente, el modelo C toma la misma forma que el anterior, pero añade los efectos directos de las dimensiones tradicionales sobre las actitudes hacia la condicionalidad.

\section{Datos}

Los datos usados provienen de una base de datos construida en el 2010 con una muestra representativa de la población de 16 años y más del principado de Cataluña ( $\mathrm{N}=1900$; más información al final del documento $\left.{ }^{1}\right)$.

Dado que el interés reside en el proceso de generación causal y en las relaciones que se establecen entre las dimensiones explicativas, independientemente de los niveles de las variables y su inferencia poblacional (el objetivo no tiene que ver con la legitimidad social de las prestaciones), el potencial de los datos sigue siendo válido y atractivo, a pesar de sus características geográficas (Cataluña, que podría no ser representativa de otros conjuntos de población) y temporales (período de crisis económica, dado que el contexto ejerce una presión).

\section{Técnicas}

Para contrastar la posibilidad de disponer de una sola variable que englobe los distintos criterios de conducta $(\mathrm{H} 1)$, se construye una escala a partir de distintos ítems y se somete a un análisis de confia- bilidad. Para ello, se usan los métodos de Análisis Factorial Exploratorio y Confirmatorio para obtener medidas de distintas propiedades relativas a la carga de un factor general.

La estrategia de construir escalas da consistencia a la operativización, por eso se utilizará también en la fase de construcción de variables para los casos en que sea posible. En estos supuestos, para el análisis de confiabilidad es suficiente el uso de alfa ordinal, medida más popular en la ciencia social. En todos ellos se sigue el mismo procedimiento: dicotomizar los ítems entre 0 (desacuerdo) y 1 (acuerdo), analizar la confiabilidad a través de la matriz de correlaciones tetracóricas, construir la nueva variable sumando las distintas variables y reescalar los valores entre 0 y 1 de nuevo.

Los sistemas de ecuaciones estructurales permiten hacer frente al resto de necesidades expresadas por las hipótesis. Primero, para comparar los distintos modelos de vías para ver cuál muestra mejor ajuste a los datos y cómo interaccionan las distintas dimensiones explicativas ( $\mathrm{H} 2)$. Segundo, para contrastar el peso explicativo de las distintas variables (Hipótesis 3 a 8).

\section{Construcción de variables}

La selección y construcción de variables se realiza de acuerdo con las necesidades teóricas y metodológicas de la investigación. En esta sección se presenta la información indispensable para la lectura de los resultados, que se amplía en el anexo 1 con valores, etiquetas y frecuencias de cada variable, y en el anexo 2 con los estadísticos descriptivos correspondientes.

Figura 1.

Modelos conceptuales de relación entre variables

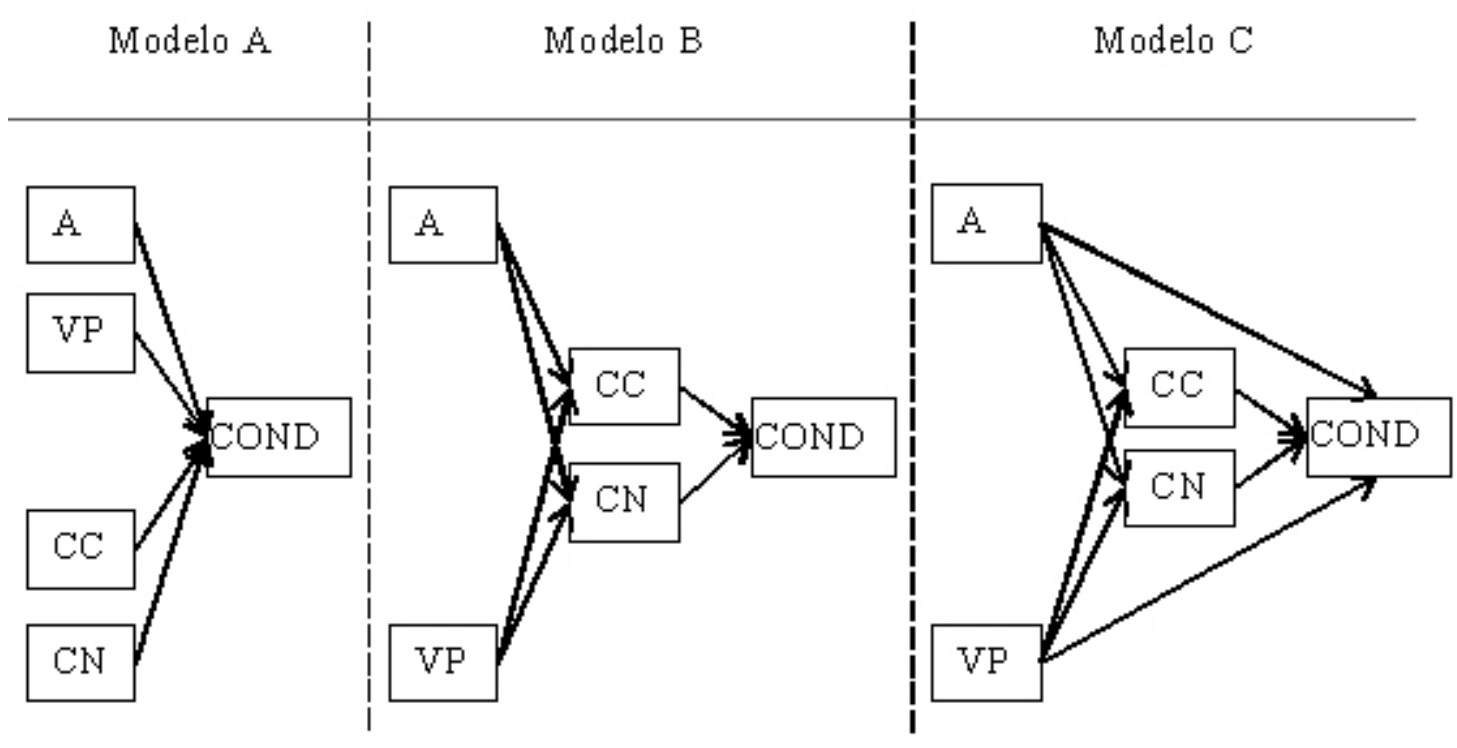

$\mathrm{A}=$ Autointerés; $\mathrm{VP}=\mathrm{Valores}$ políticos $; \mathrm{CC}=$ Criterios de conducta; $\mathrm{CN}=$ Criterios de necesidad; COND = Actitudes haciala condicionalidad 
En relación con la dimensión del merecimiento, los datos son de gran interés porque permiten capturar la importancia o uso de la conducta y la necesidad como criterios de merecimiento (aunque no el de identidad). Siguiendo las aportaciones realizadas en el marco teórico, las variables utilizadas para hacer operativos los criterios de merecimiento se refieren a situaciones generales, y no a preguntas del dominio específico de una política social. Esto último sí se realiza para la variable dependiente principal (las actitudes hacia la condicionalidad).

Un total de ocho ítems captan cuestiones relativas al valor que se le da a la conducta para juzgar a quien se debe ayudar (tres relativas al esfuerzo, dos a la reciprocidad, dos a la responsabilidad y uno a la intencionalidad). Con estos se forma una escala en la que puntuar alto identifica un individuo para el que la conducta es un criterio importante de merecimiento, considerando que los individuos son responsables de su situación, que tienen que ser recíprocos, que el esfuerzo debe ponerse en valor y que la gente tratará de sacar ventaja indebidamente, si puede (el análisis de confiabilidad indica un valor de alfa ordinal de 0,64 y, en el apartado de resultados, esta escala se somete a un análisis más complejo en relación con la H1).

Para el caso del criterio según necesidad, se consideran tres ítems con los que se capta si para el individuo es importante la situación de necesidad como criterio de merecimiento. Para el caso, la escala reúne las respuestas a la pregunta de si se debe ayudar de forma preferente a menores de edad, a mayores de 65 años o a todo ciudadano (el valor de alfa ordinal asciende a 0,83). Las respuestas en la construcción de la escala se organizan de manera que alguien que puntúa alto es alguien que considera que solo merece ayuda quien está en situación de mayor vulnerabilidad. Al contrario, puntuar bajo identifica a un individuo para el que no es relevante la necesidad para discriminar entre merecedores y no merecedores, sino que toda persona lo es.

El análisis confirma que ambos criterios conforman escalas no correlacionadas. A nivel teórico, esto es importante porque pone de manifiesto la diversidad de criterios para juzgar el merecimiento; $y$, a nivel metodológico, indica que no son reducibles entre sí.

Con relación a las actitudes hacia la condicionalidad, la encuesta permite captarlas construyendo una escala de apoyo a distintos grados de condicionalidad (un valor de alfa ordinal de 0,73 , que indica buena consistencia) a partir de ocho ítems. Los ítems que forman la escala reúnen la opinión acerca de las condiciones que deben exigirse en el caso de prestaciones por desempleo (cuatro ítems), rentas mínimas (dos ítems) y pensiones de jubilación (dos ítems). Siguiendo la conceptualización del enfoque de las condicionalidades, las categorías de respuesta dicotómica posibles son o bien ninguna condición, o bien algún tipo de condición relativa a las contribu- ciones pasadas y a la situación de necesidad (condiciones de circunstancia) o a las obligaciones como beneficiario (condiciones de conducta). La escala engloba todos los resultados, sin atender al distinto apoyo que pueda recibir cada programa: el interés reside en las condiciones, independientemente de los programas (que tienen en común que son transferencias monetarias y no servicios). A mayor puntuación, actitud más condicional.

En cuanto a la dimensión ideológica, siguiendo las indicaciones realizadas en el marco teórico, se utiliza tanto el autoposicionamiento en el eje izquierda-derecha como el grado de igualitarismo. El eje izquierdaderecha se hace operativo de forma ordinal, considerando las tres posiciones básicas de izquierda, centro y derecha (en este orden, de menos a más). Con relación al grado de igualitarismo, se forma una escala (el análisis de confiabilidad indica un valor de alfa ordinal de 0,67$)$ que reduce las respuestas dicotómicas a cinco indicadores relativos al repartimiento de la riqueza en una sola variable, de menor a mayor igualitarismo.

Finalmente, en el caso del autointerés se construyen un total de seis variables ordinales. Las categorías están ordenadas de menor a mayor autointerés hipotético hacia un grado bajo de condicionalidad de la política social. En esta dimensión, en primer lugar, se captan distintas variables que cubren situaciones laborales 0 económicas que hipotéticamente provocan mayor autointerés. Se capta el nivel de estudios (siendo la categoría "sin estudios" la de los más autointeresados; es decir, la categoría más alta), la posición en el mercado laboral del individuo (siendo los parados los más autointeresados), las prestaciones que recibe el encuestado (identificando los más dependientes como más autointeresados) y, finalmente, el nivel de ingresos netos del hogar (siendo los que viven en hogares con menos de 1000 euros al mes los más autointeresados). En segundo lugar, como variables del autointerés también se utilizan las sociodemográficas de sexo y edad, siendo las mujeres y los individuos de mayor edad categorizados como los más autointeresados, por sus posiciones de mayor vulnerabilidad estructural.

\section{Resultados}

En el marco teórico se ha expuesto la pertinencia de pensar en los criterios de conducta como una categoría conjunta (H1), avanzando hacia una conceptualización más sintética. Si bien ya se ha visto que la escala (que reúne criterios de reciprocidad, esfuerzo, responsabilidad e intencionalidad) tiene consistencia interna, en este caso interesa explorar otras propiedades. Los resultados de la tabla 1 indican que, si bien la unidimensionalidad no es muy elevada (reconociendo que existen matices para cada criterio), existe un grado considerable de homogeneidad, con una carga común de todas las variables a un concepto latente que, teóricamente, puede identificarse con el juicio basado en la conducta. 
Tabla 1.

Resultados del análisis de confiabilidad de la escala de criterios de conducta

\begin{tabular}{|l|c|}
\hline$N$ ítems & 8 \\
\hline$\alpha-$ Alfa ordinal & 0,64 \\
\hline$\omega_{\mathrm{h}}$ - Omega jerárquica & 0,52 \\
\hline$\omega_{\mathrm{t}-\text { Omega total }}$ & 0,71 \\
\hline $\begin{array}{l}\text { ECV - Varianza común } \\
\text { explicada }\end{array}$ & 0,5 \\
\hline
\end{tabular}

Nota para la interpretación: El alfa ordinal mide la consistencia interna de la escala. El análisis de omega realiza un análisis factorial y es indicativo de la homogeneidad (según la carga común a una variable latente y la estructura factorial). El estadístico ECV se refiere a la unidimensionalidad, siendo el resultado la razón del autovalor del factor general con la suma de todos los autovalores.

Es posible, por tanto, concebir una sola categoría de criterios de conducta sin perder información. Sociológicamente, lo más relevante es identificar que esto es posible porque, en común, subyace un juicio moral que opera con la mecánica básica entre conducta y resultado y la reciprocidad fuerte como motivación.

En relación con la hipótesis sobre la centralidad de los criterios de merecimiento, en la tabla 2 podemos observar que el ajuste de un modelo de vías (modelos B y C) es superior a uno que no contem- pla vías (modelo A). Esto significa que los criterios de merecimiento median entre las dimensiones tradicionales y las actitudes hacia la condicionalidad $(\mathrm{H} 2)$. Profundizando más, el modelo B es más parsimonioso y con más grados de libertad (más sobreidentificado), y sigue mostrando buen ajuste. Esto es indicativo de que una parte destacada del efecto del autointerés y la ideología se expresa de forma indirecta a través de los criterios de merecimiento. Un refuerzo adicional de esta hipótesis viene de la comparación de la capacidad predictiva $\left(\mathrm{R}^{2}\right)$ de los modelos $B$ y $C$, en los que uno contempla efectos directos de las variables tradicionales sobre la condicionalidad (B) y el otro no (C): los efectos directos no mejoran sustancialmente la $\mathrm{R}^{2}$.

Considerando lo expuesto en el marco teórico, estos resultados pueden interpretarse como evidencia a favor de la idea de que, a través del merecimiento, es posible fundamentar y comprender mejor los efectos del autointerés y la ideología. De hecho, teniendo en cuenta que la cantidad de varianza explicada de los criterios de conducta y de necesidad por parte de las dimensiones tradicionales $\left(R^{2}=0,07\right.$ y $\left.R^{2}=0,149\right)$ es más bien baja (especialmente para el caso de los criterios de conducta), hay que considerar que no solo existe una mediación con los efectos del autointerés y la ideología, sino que los criterios de merecimiento atienden a una parte importante de la variabilidad que quedaría inexplicada si no se atienden.

Tabla 2.

Índices de bondad de ajuste para los modelos de análisis construidos

\begin{tabular}{|c|c|c|c|}
\hline & MODELO A & MODELO B & MODELO C \\
\hline Grados de libertad & 23 & 15 & 7 \\
\hline \multicolumn{4}{|l|}{ Índices de ajuste absoluto } \\
\hline Chi-cuadrado & 457,950 & 119,247 & 24,941 \\
\hline $\operatorname{Pr}(>\mathrm{Chi})$ & $1,353 e-86$ & $2,650 e-86$ & 0,001 \\
\hline RMSEA & 0,102 & 0,060 & 0,037 \\
\hline \multicolumn{4}{|l|}{ Índices de ajuste incremental } \\
\hline Bentler CFI & 0,824 & 0,960 & 0,993 \\
\hline Bollen IFI & 0,827 & 0,960 & 0,993 \\
\hline \multicolumn{4}{|l|}{ Índices de parsimonia } \\
\hline AGFI & 0,880 & 0,951 & 0,978 \\
\hline \multicolumn{4}{|l|}{ Índices de ajuste comparativo } \\
\hline $\mathrm{AIC}$ & 563.950 & 221.247 & 142.941 \\
\hline \multicolumn{4}{|l|}{$\mathrm{R}^{2}$} \\
\hline Actitudes hacia la condicionalidad & 0,262 & 0,255 & 0,291 \\
\hline Criterio conducta & & 0,070 & 0,070 \\
\hline Criterio necesidad & & 0,149 & 0,149 \\
\hline
\end{tabular}

Nota para la interpretación: Un valor pequeño del chi-cuadrado indica mejor ajuste y es deseable que no sea significativo a nivel estadístico (teniendo en cuenta que, cuanto más grande la muestra, más fácil resulta que sea significativo). Para el estadístico RMSEA, se considera un buen ajuste valores inferiores a 0,08 , mientras que los valores de AGFI, Bentler CFI y Bollen IFI muestran buen ajuste con valores superiores a 0,90-0,95. Finalmente, el valor de AIC es útil para la comparación entre modelos y, cuanto menor sea su valor, mejor. Es preferible encontrar un modelo sobreidentificado: al trabajar con más grados de libertad, indica una evidencia mucho más fuerte. 
La canalización o fundamentación de los efectos del autointerés y la ideología a través del merecimiento se puede analizar en mayor detalle con los coeficientes de regresión de la tabla 3 (que también permiten contrastar las hipótesis 3, 4, 5, 6, 7 y 8).

De forma general, los individuos de derechas y los menos igualitaristas dan importancia a los criterios de conducta $(\mathrm{H} 3)$ y son más propensos a desarrollar actitudes más condicionales (H5). Específicamente, es interesante destacar que la posición de derechas tiene que ver, sobre todo, con la valoración de la conducta (el coeficiente del criterio de necesidad no es significativo). Así, la canalización del merecimiento de este efecto implica que lo relevante de ser de derechas es específicamente la valorización del esfuerzo y la responsabilidad individual.

En esta misma línea, una mirada a través del grado de igualitarismo muestra que los más igualitaristas no usan criterios de conducta y necesidad $(\mathrm{H} 3)$ y que, en consonancia, muestran actitudes hacia la condicionalidad más generosas (H5). El hecho de que el igualitarismo tenga más influencia en el criterio de necesidad que en el de conducta (coeficiente menor) indica que su efecto se da especialmente a través de la consideración de la responsabilidad pública en un mínimo social universal, que tiene que ver con el criterio de necesidad. De todas formas, su relación negativa con el criterio de conducta también indica que su efecto se basa en anular la importancia de la conducta como criterio de merecimiento.

Considerando la dimensión del autointerés, se observa que la canalización a través del merecimiento se produce de manera tal que distintas posiciones es- tructurales utilizan criterios diferentes. Los resultados identifican que esto es más claro para los juicios según necesidad: de forma significativa, los que ingresan menos en el hogar, los que están desempleados y los que no tienen estudios, no usan estos criterios (H4). Además, atendiendo a la edad y la posición en el mercado (las dos únicas variables significativas en el caso del autointerés), se puede afirmar que los más autointeresados tienen actitudes menos condicionales $(\mathrm{H} 6)$.

Volviendo a la dimensión del merecimiento, parte del impacto del autointerés en la formación de actitudes hacia la condicionalidad se canaliza a través de la aplicación del criterio de necesidad, de manera que se traduce en una apuesta para la cobertura universal de un mínimo social. Considerando la teoría, esto tiene todo el sentido, dado que interés y necesidad están íntimamente relacionados. En ambos, la motivación tiene que ver con mejorar las propias oportunidades, de manera que los más necesitados son, a la vez, los más autointeresados.

Hay que decir que la edad presenta un signo contrario (positivo) en este caso, pero interpretable igualmente como medida de autointerés expresada en el uso del criterio de necesidad. En la construcción de la escala se incluía una variable que identificaba a los mayores de 65 años como colectivo al que focalizar la ayuda. Así, teniendo en cuenta cómo ha sido construida la variable del uso del criterio de necesidad, se explica que la variable edad muestre un signo contrario al resto, tendiendo a la focalización al reconocer su propia situación. A pesar de ello, en contra de lo que cabría esperar según la hipótesis de la competitividad por los recursos, en relación con

Tabla 3.

Coeficientes de regresión estandarizados de los efectos directos del Modelo C

\begin{tabular}{|c|c|c|c|}
\hline & \multicolumn{2}{|c|}{ Merecimiento } & \multirow{2}{*}{ Condicionalidad } \\
\hline & Criterio conducta & Criterio necesidad & \\
\hline \multicolumn{4}{|l|}{ Ideología } \\
\hline Eje ideológico & $0,142^{* \star *}$ & $-0,029$ & $0,039^{* *}$ \\
\hline Igualitarismo & $-0,082^{* \star *}$ & $-0,165^{\star * *}$ & $-0,112^{\star \star \star}$ \\
\hline \multicolumn{4}{|l|}{ Autointerés } \\
\hline Sexo & $-0.066^{\star \star}$ & $-0,025$ & 0,009 \\
\hline Edad & $0,067^{* * *}$ & $0,131^{* * *}$ & $-0,098^{\star *}$ \\
\hline Ingresos & 0,021 & $-0,136^{* * *}$ & $-0,026$ \\
\hline Posición mercado & $-0,101^{* \star *}$ & $-0,069^{* * *}$ & $-0,098^{\star \star \star}$ \\
\hline Prestaciones & 0,018 & $-0,018$ & 0,002 \\
\hline Nivel formación & $0,114^{\star \star \star}$ & $-0,247^{* * *}$ & 0,028 \\
\hline \multicolumn{4}{|c|}{ Criterios de merecimiento } \\
\hline Criterio conducta & & & $0,342^{* * *}$ \\
\hline Criterio necesidad & & & $0,323^{* * *}$ \\
\hline $\mathrm{R}^{2}$ & 0,070 & 0,149 & 0,291 \\
\hline
\end{tabular}

Nota: ${ }^{*} p<0.1 ;{ }^{* *} p<0.05 ;{ }^{* * *} p<0.01$ 
las actitudes hacia la condicionalidad los resultados muestran que estos mismos individuos de mayor edad prefieren una baja condicionalidad de la política social (H6). A nivel moral, por su situación estructural específica, juzgan el merecimiento de una determinada manera (dan importancia a la necesidad), pero esto no se traduce en una mayor condicionalidad en general. En este caso, distinguir entre merecimiento y condicionalidad permite ofrecer una explicación a estos resultados ambivalentes, excluyendo la idea de la hipótesis de la competitividad.

Siguiendo con el autointerés en su relación con el merecimiento, pero centrando la mirada en los criterios de conducta, se observa que hay mayor desajuste entre los signos de los coeficientes. La hipótesis, a priori, se confirma solo parcialmente $(\mathrm{H} 4)$ : los parados y las mujeres dan menor importancia a los criterios de conducta como fuente de merecimiento, mientras los individuos de más edad y los menos formados los utilizan más. El desajuste aparente por parte de las variables de edad y nivel formativo desaparece si se considera la correlación existente entre los datos de ambas (coeficiente de Spearman de 0,309 , significativo al nivel 0,01 ), apuntando que los más mayores tienen un nivel educativo inferior. Por tanto, parece operar la misma lógica para ambas, que puede tener que ver con la importancia que los mayores, tras una vida de contribuciones, dan a la conducta como criterio de merecimiento (Jeene, van Oorschot, y Uunk 2013). De todas formas, como ya se ha apuntado, esto no se traduce en actitudes más condicionales en relación con la política social, sino que únicamente se expresa un juicio moral. De nue- vo, se observa el acierto de diferenciar merecimiento y condicionalidad para dar sentido a lo que podría resultar ambivalente si no se diferenciara.

Para seguir profundizando en el papel del merecimiento y sus interacciones, resulta útil recurrir a la comparación de los efectos directos e indirectos en la formación de las actitudes hacia la condicionalidad (gráfico 1).

El gráfico 1 ofrece una visualización de los datos adecuada para mostrar las interacciones que se producen a causa o a través del merecimiento (todos los coeficientes de efectos directos, indirectos y totales de los distintos modelos se pueden consultar en el anexo 3). En línea con lo discutido anteriormente, el nivel formativo y la edad presentan signos opuestos en el efecto directo e indirecto. En este caso, los juicios de merecimiento producen interferencias entre el autointerés y las actitudes hacia la condicionalidad, dando a las últimas un sentido distinto del que cabría esperar si se solaparan merecimiento y condicionalidad.

De forma interesante, el gráfico 1 cuantifica el nivel de canalización que se produce a través del merecimiento: si se observan los casos en los que el efecto directo e indirecto son del mismo signo, el efecto indirecto a través de la dimensión del merecimiento es casi siempre remarcable y, en diversas ocasiones, incluso superior al efecto directo. El hecho de que la importancia de los efectos directos de las variables de las dimensiones tradicionales sea muy relativa, en contra de lo que cabría esperar, remarca la centralidad del merecimiento en la

\section{Gráfico 1.}

Coeficientes estandarizados de los efectos directos e indirectos del Modelo C
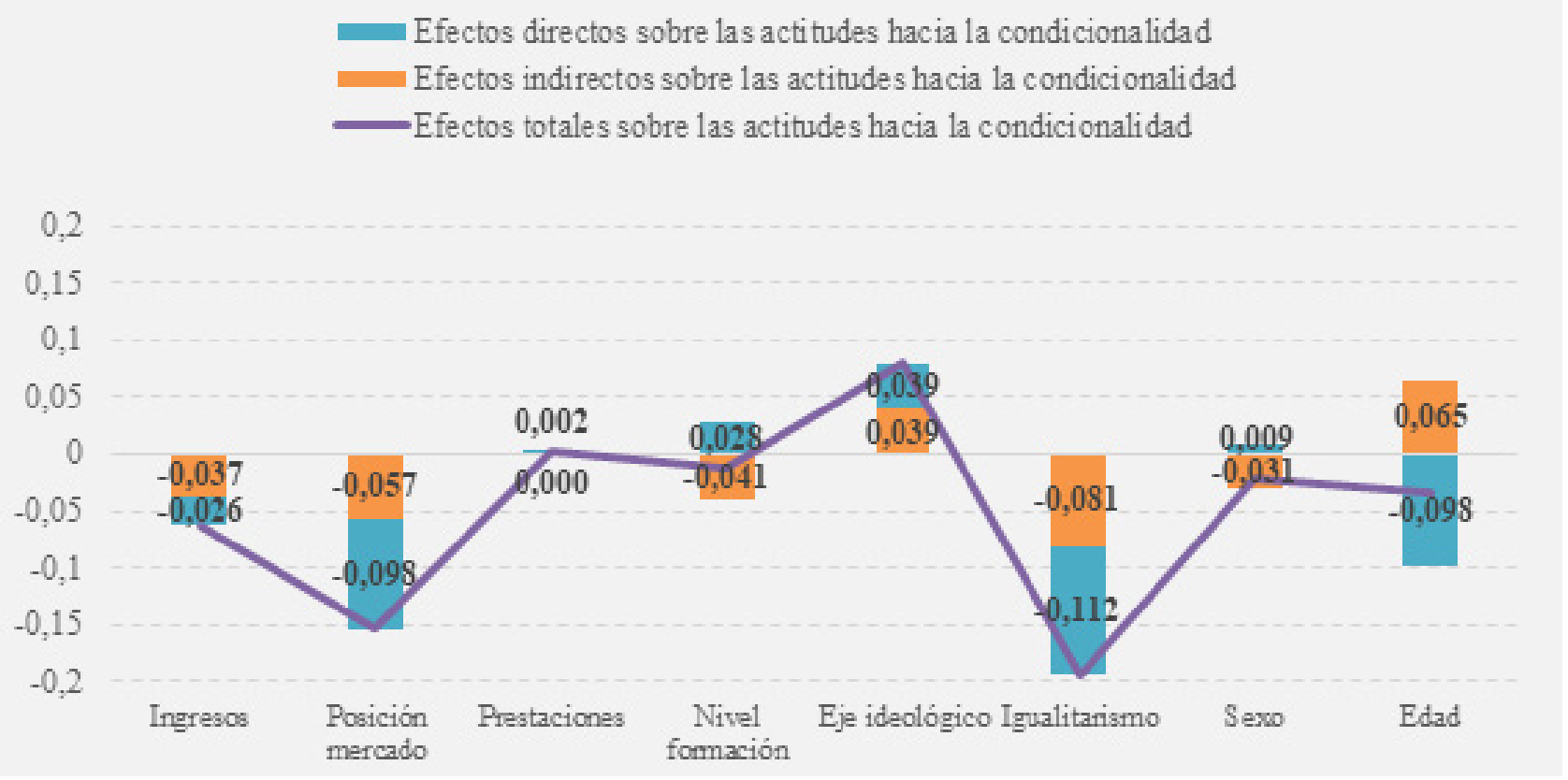
explicación de las actitudes hacia la condicionalidad, que permite fundamentar en su carácter moral una parte significativa de los efectos del autointerés $\mathrm{y}$, especialmente, de la ideología.

Además, si bien hasta ahora el foco se ha puesto en cómo el merecimiento interfiere, canaliza y fundamenta parte de los efectos de las variables tradicionales, los criterios de conducta y necesidad tienen los coeficientes de regresión más elevados $(\mathrm{H} 8)$, más del doble que el igualitarismo, que les sigue.

En conjunto, todos los resultados apuntan a la importancia tanto cualitativa (por la canalización de los efectos y las interferencias) como cuantitativa (por su peso) de los criterios de merecimiento en la explicación de las actitudes hacia la condicionalidad.

\section{Conclusiones}

Retomando los objetivos principales de la investigación, el análisis ha mostrado el gran poder explicativo de los criterios de merecimiento en el ámbito de las actitudes hacia la condicionalidad (más que el autointerés y la ideología): cuanta más importancia se da a la conducta y a la necesidad como criterios de merecimiento, mayor condicionalidad. La integración con las motivaciones prosociales y la idea de la economía moral de los EB anticipaba, en el marco teórico, las razones que hacen comprensible la centralidad de los criterios de merecimiento. Esto tiene que ver con su capacidad para fundamentar los efectos de la ideología y del autointerés, pero, especialmente, por atender a claves explicativas habitualmente desatendidas. Los criterios de merecimiento tienen que ver con las reglas que regulan la cooperación: sitúan la idea de un homo reciprocans ampliando la mirada más allá del homo economicus (autointerés) y el homo sociologicus (ideología).

La relevancia de los resultados tiene que ver, además, con el tipo de actitudes estudiadas. Las actitudes hacia la condicionalidad se han definido a partir de la tipología de condiciones identificadas por Clasen y Clegg (2007), atendiendo, en la investigación empírica, a las condiciones de circunstancia y de conducta en las prestaciones por desempleo, las rentas mínimas y las pensiones.

Dar respuesta a la pregunta de investigación ha supuesto distinguir las dimensiones de merecimiento y condicionalidad, siendo la primera explicativa de la segunda. Los criterios de merecimiento tienen que ver con juicios morales que realizan los individuos en la esfera de la opinión pública (dominio transversal), y las actitudes hacia la condicionalidad, con el diseño de la política social y las actitudes relativas a las condiciones de acceso y mantenimiento de la condición de beneficiario (dominio específico). Hay que apuntar, en este sen- tido, que ha sido posible concebir una categoría general de criterios de conducta, sintetizando el esquema original.

Si bien los criterios de merecimiento según conducta y necesidad han sido la dimensión explicativa central con diferencia, se ha podido observar que el autointerés y la ideología se relacionan con las actitudes hacia la condicionalidad según lo esperado (los individuos más igualitaristas y de izquierdas, así como los situados en posiciones estructurales más desfavorables, son menos condicionales). También se ha corroborado que distintos grupos sociales usan distintos criterios, aunque los resultados obligan a matizar la afirmación en dos direcciones. Primero, el autointerés y la ideología tienen una capacidad limitada para explicar los criterios que se usan. Segundo, gracias a la distinción entre merecimiento y condicionalidad, se observa que se pueden apoyar determinados criterios de merecimiento según la posición estructural sin que automáticamente impliquen un grado específico de condicionalidad de la política social (aportando evidencia para refutar la hipótesis de la competitividad por los recursos).

Teniendo en cuenta que la retroalimentación entre opinión pública y diseño de la política social provoca un acercamiento entre ambas, el potencial de los criterios de merecimiento reluce al considerar el encaje entre el esquema de los criterios de merecimiento y la tipología de condiciones de la política social detectada por Clasen y Clegg (2007).

En primer lugar, la importancia de los criterios de merecimiento es una muestra de las resistencias o apoyos que el diseño e implantación de una política social puede encontrar, dado que apuntan a los conceptos con los que opera la opinión pública. En este sentido, la existencia e importancia de los criterios de merecimiento hace plausible el giro hacia las políticas de activación laboral e inversión social desde la opinión pública. En segundo lugar, en relación con la comunicación política, el análisis empírico da cuenta del poder que pueden tener los mensajes relativos a motivar el desarrollo de actitudes anteponiendo las cuestiones basadas en el merecimiento. Cuanta mayor parte de la población perciba conductas que no generan merecimiento entre los beneficiarios de una política social, más condicionales y menos a favor de esa política se mostraran. Por contra, si los mensajes se dirigen a poner en valor la situación de necesidad de la población beneficiaria de prestaciones (y no sus conductas), un mayor número de gente formará sus actitudes basándose en la solidaridad. Asimismo, es posible pensar en estrategias discursivas que no traten de anteponer el merecimiento, sino el autointerés o la ideología (Chong, Citrin y Conley 2001). De todas formas, Del Pino y Calzada (2013) ponen de relieve, específicamente, el éxito 
que puede tener manipular la percepción del merecimiento según intereses políticos para favorecer unas u otras reformas. La posibilidad de manipular la percepción del merecimiento es la base de distintos estudios experimentales (Petersen et al. 2010; Slothuus 2007), y los resultados demoscópicos de esta investigación apuntan al poder que tienen los criterios de merecimiento en la formación de actitudes.

Finalmente, teniendo en cuenta las limitaciones del presente estudio, así como sus resultados, cabe remarcar el interés de futuras investigaciones:

\section{NOTAS}

[1] Los datos se obtuvieron a través de encuestas telefónicas llevadas a cabo entre los días 15 y 29 de marzo de 2010. Se trata de un muestreo por cuotas, estratificado por provincias y dimensión del municipio, con selección de municipios de forma proporcional y de individuos aleatoriamente siguiendo cuotas cruzadas de sexo y edad. Más información: https://tinyurl.com/y9gofa9e.

\section{RefERENCIAS BibLIOGRÁficas}

Andreß, H-J. y T. Heien. 2001. "Four Worlds of Welfare State Attitudes? A Comparison of Germany, Norway, and the United States". European Sociological Review 17(4):337-356. https://doi.org/10.1093/esr/17.4.337

Arts, W. y J. Gelissen. 2001. "Welfare States, Solidarity and Justice Principles: Does the Type Really Matter?". Acta Sociologica 44(4):283-299. https://doi. org/10.1177/000169930104400401

Bonoli, G. 2010. "The Political Economy of Active Labor-Market Policy". Politics \& Society 38(4):435-457. https:// doi.org/10.1177/0032329210381235

Bowles, S. y H. Gintis. 2000. "Reciprocity, self-interest and the welfare state". Nordic Journal of Political Economy 26:33-53.

Calzada, I., M. Gómez-Garrido, L. Moreno y F.J. Moreno-Fuentes. 2014. "It Is Not Only about Equality. A Study on the (Other) Values That Ground Attitudes to the Welfare State". International Journal of Public Opinion Research 26(2):178-201. https://doi.org/10.1093/ijpor/edt044

Calzada, I. y E. Del Pino. 2016. "Actitudes ante la redistribución: ¿Cómo ha afectado la crisis?”. Revista Española del Tercer Sector (33):65-90.

Chong, D., J. Citrin y P. Conley. 2001. "When Self-Interest Matters". Political Psychology 22(3):541-570. https://doi. org/10.1111/0162-895X.00253

Chong, D. y J.N. Druckman. 2007. "Framing theory". Annual Review of Political Science 10:103-126. https://doi. org/10.1146/annurev.polisci.10.072805.103054

Clasen, J. y D. Clegg. 2007. "Chapter 8: Levels and levers of conditionality: measuring change within welfare states". Pp. 166-197 en Investigating welfare state change. The dependent variable problem in comparative analysis, editado por J. Clasen y N. A. Siegel. Cheltenham: Edward Elgar.
- Observar el efecto del contexto en la valoración de distintos criterios de merecimiento, comparando su presencia en distintos países. Si los criterios de merecimiento son usados de forma transversal, ¿es posible entender a través de ellos el apoyo amplio y estable a los EB y, a su vez, las diferencias entre países?

- Diseñar encuestas u otros instrumentos especialmente pensados para captar criterios de merecimiento de forma transversal y actitudes hacia las condiciones específicas de categoría, circunstancia y conducta.
Conybeare, J.A. C. 2007. «Efficiency, Entitlements and Deservingness: Perspectives on International Distributive Justice». Review of International Political Economy 14(3):389-411. https://doi.org/10.1080/09692290701395668

Cosmides, L. y J. Tooby. 2006. "Heuristics and the Law". editado por G. Gigerenzer y C. Engel. Cambridge: MIT Press.

Delton, A.W., L. Cosmides, M. Guemo, T.E. Robertson y J. Tooby. 2012. "The psychosemantics of free riding: Dissecting the architecture of a moral concept". Journal of personality and social psychology 102:1252-1270. https://doi.org/10.1037/a0027026

Delton, A.W., M.B. Petersen, P. DeScioli y T.E. Robertson. 2018. "Need, Compassion, and Support for Social Welfare". Political Psychology 39(4):907-924. https:// doi.org/10.1111/pops.12450

Esping-Andersen, G. 1990. The three worlds of welfare capitalism. Cambridge: Polity Press.

Feather, N.T. 2003. "Distinguishing between deservingness and entitlement: earned outcomes versus lawful outcomes". European Journal of Social Psychology 33:367-385. https://doi.org/10.1002/ejsp.152

Feather, N.T. 2006. "Deservingness and emotions: Applying the structural model of deservingness to the analysis of affective reactions to outcomes". European Review of Social Psychology 17:38-73. https://doi. org/10.1080/10463280600662321

Fletcher, D.R. y S. Wright. 2018. "A hand up or a slap down? Criminalising benefit claimants in Britain via strategies of surveillance, sanctions and deterrence". Critical Social Policy 38(2):323-344. https://doi. org/10.1177/0261018317726622

Gaeta, G.L. 2012. "In the mood for redistribution. An empirical analysis of individual preferences for redistribution in Italy". Economics Bulletin 32(3):2382-2398. 
González Begega, S. y E. Del Pino. 2017. "From letting Europe in to policy conditionality. Welfare reform in Spain under Austerity". Working paper 2017-01. Instituto de Políticas y Bienes Públicos (IPP) CSIC. Madrid.

Jæger, M.M. 2006. "What Makes People Support Public Responsibility for Welfare Provision: Self-interest or Political Ideology? A longitudinal approach". Acta Sociologica 49(3):321-338. https://doi. org/10.1177/0001699306067718

Jæger, M.M. 2008. "Does left-right orientation have a causal effect on support for redistribution? Causal analysis with cross-sectional data using instrumental variables". International Journal of Public Opinion Research 20(3):363-374. https://doi.org/10.1093/ijpor/edn030

Jæger, M.M. 2009. “United But Divided: Welfare Regimes and the Level and Variance in Public Support for Redistribution". European Sociological Review 25(6):723-737. https://doi.org/10.1093/esr/jcn079

Jeene, M., W. van Oorschot, y W. Uunk. 2013. "Popular Criteria for the Welfare Deservingness of Disability Pensioneres: The Influence of Structural and Cultural Factors". Social Indicators Research 110(3):1103-1117. https://doi.org/10.1007/s11205-011-9974-7

Kulin, J. y S. Svallfors. 2013. "Class, Values, and Attitudes Towards Redistribution: A European Comparison”. European Sociological Review 29(2):155-167. https://doi. org/10.1093/esr/jcr046

León, F.J. 2012. "Reciprocity and Public Support for the redistributive role of the State". Journal of European Social Policy 22(2):198-215. https://doi. org/10.1177/0958928711433657

Leoni, T. 2015. "Welfare state adjustment to new social risks in the post-crisis scenario. A review with focus on the social investment perspective". WWWforEurope Working Papers series 89, WWWforEurope.

Linos, K. y M. West. 2003. "Self-Interest, Social Beliefs, and Attitudes to Redistribution: Re-Addressing the Issue of Cross-National Variation". European Sociological Review 19(4):393-409. https://doi.org/10.1093/ esr/19.4.393

Mau, S. 2003. The Moral Economy of Welfare States: Britain and Germany Compared. Londres: Routledge.

Meuleman, B. et al. 2018. Pasado, presente y futuro de las actitudes sobre el bienestar social en Europa: Principales resultados de la octava edición de la Encuesta Social Europea. Londres.

Moreno, L. y A. Serrano-Pascual. 2007. “Europeización del Bienestar y activación". Política y Sociedad 44(2): 31-44.

Noguera, J.A. dir. 2011. Valors i actituds sobre justícia distributiva: prestacions socials i fiscalitat. Barcelona: Centre d'Estudis d'Opinió, Generalitat de Catalunya.

Noya, J. 2004. Ciudadanos ambivalentes. Actitudes ante la igualdad y el Estado de Bienestar en España. Colección. Madrid: CIS-Siglo XXI de España Editores.

Petersen, M.B. y L. Aarøe. 2012. "Is the political animal politically ignorant? Applying Evolutionary Psychology to the Study of Political Attitudes". Evolutionary Psychology 10(5):802-817. https://doi. org/10.1177/147470491201000504

Petersen, M.B., R. Slothuus, R. Stubager y L. Togeby. 2010. "Deservingness versus values in public opinion on welfare: The automaticity of the deservingness heuris- tic". European Journal of Political Research 50:24-52. https://doi.org/10.1111/j.1475-6765.2010.01923.x

Petersen, M. B., R. Slothuus y L. Togeby. 2010. "Political Parties and Value Consistency in Public Opinion Formation". Public Opinion Quarterly 74(3):530-550. https:// doi.org/10.1093/poq/nfq005

Petersen, M.B., D. Sznycer, L. Cosmides y J. Tooby. 2012. "Who deserves help? Evolutionary Psychology, social emotions and public opinion about welfare". Political Psychology 33(3):395-418. https://doi.org/10.1111/ j.1467-9221.2012.00883.x

Pino, E. del e I. Calzada. 2013. "La imaginación da el poder: estrategias políticas para evitar el castigo electoral y reformar el estado de bienestar" en Los Estados de Bienestar en la encrucijada. Políticas Sociales en perspectiva comparada, editado por E. del Pino y M. J. R. Lara. Madrid: Tecnos.

Reeskens, T. y W. van Oorschot. 2012. "Disentangling the 'New Liberal Dilemma': On the relation between general welfare redistribution preferences and welfare chauvinism". Journal of Comparative Sociology 53(2):120139. https://doi.org/10.1177/0020715212451987

Reeskens, T. y W. van Oorschot. 2015. 'Immigrants' Attitudes towards Welfare Redistribution. An Exploration of Role of Government Preferences among Immigrants and Natives across 18 European Welfare States". European Sociological Review 31(4):433-445. https://doi. org/10.1093/esr/jcv003

Roosma, F. 2016. A Multidimensional Perspective on the Social Legitimacy of Welfare States in Europe. Ridderkerk: Ridderprint.

Schwartz, S. 2006. "A Theory of Cultural Value Orientations: Explication and Applications". Comparative Sociology 5(2-3):137-182. https://doi. org/10.1163/156913306778667357

Slothuus, R. 2007. "Framing Deservingness to Win Support for Welfare State Retrenchment". Scandinavian Political Studies 30(3):323-344. https://doi.org/10.1111/j.14679477.2007.00183.x

Stegmueller, D., P. Scheepers, S. Roßteutscher y E. de Jong. 2012. "Support for Redistribution in Western Europe: Assessing the role of religion." European Sociological Review 28(4):482-497. https://doi.org/10.1093/esr/ jcr011

Stiefken, P. 2014. "Altruismo y solidaridad en el Estado de Bienestar". Ph.D. dissertation. Departamento de Sociología. Universidad Autónoma de Barcelona. Barcelona.

Sundberg, T. 2014. "Attitudes to the Welfare State: A Systematic Review Approach to the Example of Ethnically Diverse Welfare States". Sociological Research Online 19(1):202-213. https://doi.org/10.5153/sro.3337

Svallfors, S. 1997. "Worlds of Welfare and Attitudes to Redistribution: A Comparison of Eight Western Nations". European Sociological Review 13(3):283-304. https://doi. org/10.1093/oxfordjournals.esr.a018219

Taylor-Gooby, P., B. Hvinden, S. Mau, B. Leruth, M. A. Schoyen, y A. Gyory. 2018. «Moral economies of the welfare state: A qualitative comparative study». Acta Sociologica 62(2):119-134. https://doi. org/10.1177/0001699318774835

Van Oorschot, W. 1998. "Deservingness and conditionality of solidarity". Sociale Wetenschappen 41(3):54-78. 
Van Oorschot, W. 2000. «Who should get what and why? On deservingness criteria and the conditionality of solidarity among the public». Policy and Politics 28(1):33-49.

Van Oorschot, W. y F. Roosma. 2015. "The social legitimacy of differently targeted benefits". ImPRovE Working Paper No. 15/11. Antwerp: Herman Deleeck Centre for Social Policy (University of Antwerp).

Weber, C.R. y C.M. Federico. 2013. "Moral Foundations and Heterogeneity in Ideological Preferences". Political Psychology 34(1):107-126. https://doi.org/10.1111/ j.1467-9221.2012.00922.x
Wright, S. 2016. "Conceptualising the active welfare subject: welfare reform in discourse, policy and lived experience." Policy and Politics 44(2):235-252. https://doi.or g/10.1332/030557314X13904856745154

Yamagishi, T., N. Mifune, J.H. Liu y J. Pauling. 2008. "Exchanges of group-based favours: Ingroup bias in the prisoner's dilemma game with minimal groups in Japan and New Zealand". Asian Journal of Social Psychology 11:196-207. https://doi.org/10.1111/j.1467839X.2008.00258.x

\section{Anexos}

Anexo 1.

Codificación de variables, frecuencias y construcción de escalas

\begin{tabular}{|c|c|c|c|}
\hline \multicolumn{4}{|c|}{ Codificación de variables } \\
\hline Variable & Valores y etiquetas & $\mathrm{N}$ & Porcentajes \\
\hline \multirow{4}{*}{ Edad } & $1=$ De 16 a 34 & 608 & $32 \%$ \\
\hline & 2=De 35 a 49 & 541 & $28,5 \%$ \\
\hline & 3=De 50 a 64 & 383 & $20,2 \%$ \\
\hline & 4=De 65 a 99 & 368 & $19,4 \%$ \\
\hline \multirow{2}{*}{ Sexo } & $0=$ Hombre & 952 & $50,1 \%$ \\
\hline & 1=Mujer & 948 & $49,9 \%$ \\
\hline \multirow{4}{*}{$\begin{array}{l}\text { Ingresos netos del hogar } \\
\text { mensuales }\end{array}$} & 1=Más de 3000 & 411 & $21,7 \%$ \\
\hline & 2=De 2000 a 3000 & 482 & $25,4 \%$ \\
\hline & 3=De 1000 a 2000 & 630 & $33,2 \%$ \\
\hline & 4=Menos de 1000 & 377 & $19,8 \%$ \\
\hline \multirow{4}{*}{ Posición en el mercado } & 1=Empresarios y autónomos con o sin trabajadores y profesionales & 205 & $10,8 \%$ \\
\hline & 2=Asalariados & 790 & $41,6 \%$ \\
\hline & $3=$ Parados & 208 & $10,9 \%$ \\
\hline & Perdidos & 697 & $36,7 \%$ \\
\hline \multirow{3}{*}{ Número de prestaciones } & $0=$ Ninguna prestación & 1130 & $59,5 \%$ \\
\hline & 1=Una prestación & 704 & $37,1 \%$ \\
\hline & 2=Dos o más prestaciones & 66 & $3,5 \%$ \\
\hline \multirow{5}{*}{ Nivel de estudios } & 1= Estudios universitarios & 437 & $23 \%$ \\
\hline & 2=Bachillerato, BUP y FP2 & 477 & $25,1 \%$ \\
\hline & $3=\mathrm{ESO}$, Bachillerato elemental, EGB y FP1 & 816 & $42,9 \%$ \\
\hline & $4=$ Sin estudios & 168 & $8,8 \%$ \\
\hline & Perdidos & 2 & $0,1 \%$ \\
\hline \multirow{4}{*}{ Eje ideológico } & 1=Izquierda & 813 & $42,8 \%$ \\
\hline & $2=$ Centro & 439 & $23,1 \%$ \\
\hline & 3=Derecha & 271 & $14,3 \%$ \\
\hline & Perdidos & 377 & $19,8 \%$ \\
\hline
\end{tabular}




\begin{tabular}{|c|c|c|c|c|}
\hline \multirow{2}{*}{ Escala } & \multirow{2}{*}{ Ítems } & \multicolumn{3}{|c|}{ Porcentajes y frecuencias } \\
\hline & & Desacuerdo (0) & Acuerdo (1) & Perdidos \\
\hline \multirow{5}{*}{$\begin{array}{l}\text { Grado de igualitarismo } \\
\text { (Escala) }\end{array}$} & $\begin{array}{l}\text { En general, ¿renunciaría usted a parte de sus } \\
\text { ingresos si eso supusiera un repartimiento social } \\
\text { más igualitario? }\end{array}$ & $\begin{array}{l}N=765 \\
40,3 \%\end{array}$ & $\begin{array}{l}N=1034 \\
54,4 \%\end{array}$ & $\begin{array}{l}N=101 \\
5,3 \%\end{array}$ \\
\hline & $\begin{array}{l}\text { Se debería establecer un límite máximo a la rique- } \\
\text { za que un individuo puede acumular. }\end{array}$ & $\begin{array}{l}N=773 \\
40,7 \%\end{array}$ & $\begin{array}{l}N=1039 \\
54,7 \%\end{array}$ & $\begin{array}{l}N=88 \\
4,6 \%\end{array}$ \\
\hline & $\begin{array}{l}\text { Todas las personas deberían recibir la misma } \\
\text { proporción de la riqueza que genera la economía } \\
\text { del país. }\end{array}$ & $\begin{array}{l}N=750 \\
39,5 \%\end{array}$ & $\begin{array}{l}N=1063 \\
55,9 \%\end{array}$ & $\begin{array}{l}N=87 \\
4,5 \%\end{array}$ \\
\hline & $\begin{array}{l}\text { Deberían reducirse las desigualdades entre las } \\
\text { personas más ricas y las más pobres. }\end{array}$ & $\begin{array}{l}N=182 \\
9,6 \%\end{array}$ & $\begin{array}{l}\mathrm{N}=1667 \\
87,2 \%\end{array}$ & $\begin{array}{l}N=61 \\
3,2 \%\end{array}$ \\
\hline & $\begin{array}{l}\text { ¿Qué cree que es más importante, el crecimiento } \\
\text { económico o el reparto de la riqueza? } \\
0=E \text { crecimiento } \\
1=\text { El reparto }\end{array}$ & $\begin{array}{l}N=743 \\
39,1 \%\end{array}$ & $\begin{array}{l}N=917 \\
48,3 \%\end{array}$ & $\begin{array}{l}N=240 \\
12,6 \%\end{array}$ \\
\hline \multirow{8}{*}{$\begin{array}{l}\text { Escala de criterios } \\
\text { conducta }\end{array}$} & $\begin{array}{l}\text { La gente tiene derecho a conservar lo que ha } \\
\text { ganado (esfuerzo). }\end{array}$ & $\begin{array}{l}N=109 \\
5,7 \%\end{array}$ & $\begin{array}{l}N=1752 \\
92,2 \%\end{array}$ & $\begin{array}{l}\mathrm{N}=39 \\
2,1 \%\end{array}$ \\
\hline & $\begin{array}{l}\text { Creo que las personas tienen que ganarse el } \\
\text { derecho a ser ayudadas (esfuerzo). }\end{array}$ & $\begin{array}{l}N=425 \\
22,4 \%\end{array}$ & $\begin{array}{l}\mathrm{N}=1404 \\
73,9 \%\end{array}$ & $\begin{array}{l}\mathrm{N}=71 \\
3,7 \%\end{array}$ \\
\hline & $\begin{array}{l}\text { Es justo que las personas que más se esfuerzan } \\
\text { obtengan una recompensa superior (esfuerzo). }\end{array}$ & $\begin{array}{l}N=126 \\
6,6 \%\end{array}$ & $\begin{array}{l}N=1740 \\
91,6 \%\end{array}$ & $\begin{array}{l}N=34 \\
1,8 \%\end{array}$ \\
\hline & $\begin{array}{l}\text { Nadie debería recibir ayuda sin ofrecer nada a } \\
\text { cambio (reciprocidad). }\end{array}$ & $\begin{array}{l}N=944 \\
49,7 \%\end{array}$ & $\begin{array}{l}N=843 \\
44,4 \%\end{array}$ & $\begin{array}{c}N=113 \\
5,9 \%\end{array}$ \\
\hline & $\begin{array}{l}\text { Las personas que no han contribuido al bienestar } \\
\text { colectivo no deberían tener derecho a recibir ayu- } \\
\text { das de la Administración Pública (reciprocidad) }\end{array}$ & $\begin{array}{l}N=904 \\
47,6 \%\end{array}$ & $\begin{array}{l}N=849 \\
44,7 \%\end{array}$ & $\begin{array}{l}N=147 \\
7,7 \%\end{array}$ \\
\hline & $\begin{array}{l}\text { Las personas pobres son responsables de su } \\
\text { situación (responsabilidad). }\end{array}$ & $\begin{array}{l}N=1355 \\
71,3 \%\end{array}$ & $\begin{array}{c}N=342 \\
18 \%\end{array}$ & $\begin{array}{l}N=203 \\
10,7 \%\end{array}$ \\
\hline & $\begin{array}{l}\text { Quien sea responsable de su situación no debe } \\
\text { recibir ninguna prestación pública (responsabili- } \\
\text { dad). }\end{array}$ & $\begin{array}{c}N=1057 \\
55,6 \%\end{array}$ & $\begin{array}{l}N=728 \\
38,3 \%\end{array}$ & $\begin{array}{l}N=115 \\
6,1 \%\end{array}$ \\
\hline & $\begin{array}{l}\text { ¿Cree que la mayoría de la gente se } \\
\text { aprovecharía de usted si tuviera la oportunidad } \\
\text { de hacerlo? (intencionalidad) }\end{array}$ & $\begin{array}{c}\mathrm{N}=627 \\
33 \%\end{array}$ & $\begin{array}{l}N=1214 \\
63,9 \%\end{array}$ & $\begin{array}{l}\mathrm{N}=59 \\
3,1 \%\end{array}$ \\
\hline \multirow{3}{*}{$\begin{array}{l}\text { Escala de criterios } \\
\text { necesidad }\end{array}$} & $\begin{array}{l}\text { La Administración debería pagar a todos los } \\
\text { ciudadanos una renta suficiente para cubrir sus } \\
\text { necesidades, sin ninguna condición. } \\
\text { "En este caso, el valor } 1 \text { es para la categoría "en } \\
\text { desacuerdo". }\end{array}$ & $\begin{array}{c}N=1063^{*} \\
55,9 \%\end{array}$ & $\begin{array}{l}N=774 \\
40,7 \%\end{array}$ & $\begin{array}{l}N=63 \\
3,3 \%\end{array}$ \\
\hline & $\begin{array}{l}\text { La Administración debería pagar a todas las } \\
\text { personas mayores de } 65 \text { años una renta sufici- } \\
\text { ente para cubrir sus necesidades, sin ninguna } \\
\text { condición. }\end{array}$ & $\begin{array}{l}N=505 \\
26,6 \%\end{array}$ & $\begin{array}{c}N=1347 \\
70,9 \%\end{array}$ & $\begin{array}{l}N=48 \\
2,5 \%\end{array}$ \\
\hline & $\begin{array}{l}\text { A cada familia, la Administración debería de } \\
\text { pagar una renta para cubrir las necesidades } \\
\text { básicas de cada menor que haya, sin ninguna } \\
\text { condición. }\end{array}$ & $\begin{array}{l}N=696 \\
36,6 \%\end{array}$ & $\begin{array}{c}N=1132 \\
59,6 \%\end{array}$ & $\begin{array}{l}N=72 \\
3,8 \%\end{array}$ \\
\hline
\end{tabular}




\begin{tabular}{|c|c|c|c|c|}
\hline \multirow{2}{*}{ Escala } & \multirow{2}{*}{ Ítems } & \multicolumn{3}{|c|}{ Porcentajes y frecuencias } \\
\hline & & Desacuerdo $(0)$ & Acuerdo (1) & Perdidos \\
\hline \multirow{8}{*}{$\begin{array}{c}\text { Escala de } \\
\text { condicionalidad }\end{array}$} & $\begin{array}{l}\text { ¿Cree usted que todas las personas en paro } \\
\text { deberían tener derecho a una prestación por } \\
\text { desempleo? }\end{array}$ & $\begin{array}{l}N=679 \\
35,7 \%\end{array}$ & $\begin{array}{l}N=1195 \\
62,9 \%\end{array}$ & $\begin{array}{l}N=26 \\
1,4 \%\end{array}$ \\
\hline & $\begin{array}{l}\text { Cree usted que las prestaciones de paro de- } \\
\text { berían... } \\
0=\text { ser indefinidas hasta que la persona en- } \\
\text { cuentre trabajo. } \\
1=\text { limitarse en el tiempo. }\end{array}$ & $\begin{array}{l}N=693 \\
36,5 \%\end{array}$ & $\begin{array}{l}N=1144 \\
60,2 \%\end{array}$ & $\begin{array}{l}N=63 \\
3,3 \%\end{array}$ \\
\hline & $\begin{array}{l}\text { Cree usted que tienen derecho a cobrar presta- } \\
\text { ciones por desempleo... } \\
0=\text { todas las personas. } \\
1=\text { solo las paradas que no dispongan de su- } \\
\text { ficientes recursos o hayan cotizado suficiente } \\
\text { tiempo. }\end{array}$ & $\begin{array}{l}N=802 \\
42,2 \%\end{array}$ & $\begin{array}{l}N=1050 \\
55,3 \%\end{array}$ & $\begin{array}{l}N=48 \\
2,5 \%\end{array}$ \\
\hline & $\begin{array}{l}\text { En su opinión, las prestaciones por desempleo } \\
\text { deberían ser... } \\
\qquad \begin{array}{l}0=\text { para todas las personas. } \\
1=\text { solo o preferentemente para las paradas } \\
\text { con cargas familiares. }\end{array}\end{array}$ & $\begin{array}{l}N=1337 \\
70,4 \%\end{array}$ & $\begin{array}{l}N=520 \\
27,4 \%\end{array}$ & $\begin{array}{c}N=43 \\
97,7 \%\end{array}$ \\
\hline & $\begin{array}{l}\text { Usted cree que deben tener derecho a recibir } \\
\text { una renta mínima... } \\
0=\text { todas las personas. } \\
1=\text { solo aquellas personas pobres que hayan } \\
\text { contribuido a la sociedad con un trabajo pro- } \\
\text { ductivo. }\end{array}$ & $\begin{array}{c}1149 \\
60,5 \%\end{array}$ & $\begin{array}{c}664 \\
34,9 \%\end{array}$ & $\begin{array}{c}87 \\
4,6 \%\end{array}$ \\
\hline & $\begin{array}{l}\text { A su parecer, debería pagarse una renta míni- } \\
\text { ma... } \\
\qquad \begin{array}{l}0=a \text { todas las personas. } \\
1=\text { solo a aquellas que se comprometan a re- } \\
\text { alizar actividades de formación y reinserción } \\
\text { laboral. }\end{array}\end{array}$ & $\begin{array}{c}N=494 \\
26 \%\end{array}$ & $\begin{array}{l}N=1338 \\
70,4 \%\end{array}$ & $\begin{array}{l}N=68 \\
3,6 \%\end{array}$ \\
\hline & $\begin{array}{l}\text { Cree que deben tener derecho a cobrar pensio- } \\
\text { nes mínimas de jubilación... } \\
\text { 0=todas las personas. } \\
\text { 1=Solo las personas mayores de edad que } \\
\text { hayan cotizado el suficiente tiempo o no dis- } \\
\text { pongan de recursos suficientes. }\end{array}$ & $\begin{array}{l}N=1237 \\
65,1 \%\end{array}$ & $\begin{array}{l}N=638 \\
33,6 \%\end{array}$ & $\begin{array}{l}N=25 \\
1,3 \%\end{array}$ \\
\hline & $\begin{array}{l}\text { ¿Está usted de acuerdo en que las cotizaciones } \\
\text { sociales que paga cada persona deberían } \\
\text { destinarse a financiar solo su pensión, y no la de } \\
\text { los otros? }\end{array}$ & $\begin{array}{c}N=1022 \\
53,8 \%\end{array}$ & $\begin{array}{l}N=775 \\
40,8 \%\end{array}$ & $\begin{array}{c}N=1797 \\
5,4 \%\end{array}$ \\
\hline
\end{tabular}


Anexo 2

Estadísticos descriptivos

\begin{tabular}{|c|c|c|c|c|c|}
\hline & $\mathbf{N}$ & Min. & Max. & Media & $\begin{array}{c}\text { Desviación } \\
\text { típica }\end{array}$ \\
\hline Edad & 1900 & 1 & 4 & 2,27 & 1,107 \\
\hline Sexo & 1900 & 0 & 1 &, 50 &, 500 \\
\hline Ingresos netos del hogar mensuales & 1900 & 1 & 4 & 2,51 & 1,039 \\
\hline Posición en el mercado & 1203 & 1 & 3 & 2,0025 &, 58616 \\
\hline Número de prestaciones & 1900 & 0 & 2 & ,44 &, 562 \\
\hline Nivel de estudios & 1898 & 1 & 4 & 2,38 & ,934 \\
\hline Eje ideológico & 1523 & 1 & 3 & 1,64 &, 765 \\
\hline Escala de igualitarismo & 1450 & 0 & 1 & ,6399 & ,26172 \\
\hline Escala de criterios de conducta & 1389 & 0 & 1 & ,6029 & , 19496 \\
\hline Escala de criterios de necesidad & 1750 & 0 & 1 & ,4116 & ,36841 \\
\hline Escala de condicionalidad & 1533 & 0 & 1 &, 5196 & ,22900 \\
\hline
\end{tabular}

Anexo 3

Coeficientes estandarizados de los efectos totales, directos e indirectos de los modelos $B$ y $C$

\begin{tabular}{|c|c|c|c|c|c|c|c|c|c|c|}
\hline \multicolumn{11}{|c|}{ MODELO B } \\
\hline & $\mathrm{CC}$ & $\mathrm{CN}$ & INGRES & POSMERC & PREST & FORM & IZQDER & IGUALIT & SEXO & EDAD \\
\hline \multicolumn{11}{|c|}{ Efectos totales } \\
\hline COND & 0,358 & 0,356 & $-0,041$ & $-0,061$ & $-9,86 e-5$ & $-0,047$ & 0,041 & $-0,088$ & $-0,033$ & 0,071 \\
\hline $\mathrm{CC}$ & & & 0,021 & $-0,101$ & 0,018 & 0,114 & 0,142 & $-0,082$ & $-0,066$ & 0,067 \\
\hline $\mathrm{CN}$ & & & $-0,148$ & $-0,099$ & $-0,018$ & $-0,247$ & $-0,029$ & $-0,165$ & $-0,025$ & 0,131 \\
\hline \multicolumn{11}{|c|}{ Efectos directos } \\
\hline COND & 0,358 & 0,356 & & & & & & & & \\
\hline $\mathrm{CC}$ & & & 0,021 & $-0,101$ & 0,018 & 0,114 & 0,142 & $-0,082$ & $-0,066$ & 0,067 \\
\hline $\mathrm{CN}$ & & & $-0,148$ & $-0,099$ & $-0,018$ & $-0,247$ & $-0,029$ & $-0,165$ & $-0,025$ & 0,131 \\
\hline \multicolumn{11}{|c|}{ Efectos indirectos } \\
\hline COND & & & $-0,041$ & $-0,061$ & $-9,86 e-5$ & $-0,047$ & 0,041 & $-0,088$ & $-0,033$ & 0,071 \\
\hline \multicolumn{11}{|c|}{ MODELO C } \\
\hline \multicolumn{11}{|c|}{ Efectos totales } \\
\hline COND & 0,342 & 0,323 & $-0,063$ & $-0,154$ & 0,002 & $-0,013$ & 0,079 & $-0,194$ & $-0,023$ & $-0,033$ \\
\hline $\mathrm{CC}$ & & & 0,021 & $-0,101$ & 0,018 & 0,114 & 0,142 & $-0,082$ & $-0,066$ & 0,067 \\
\hline $\mathrm{CN}$ & & & $-0,148$ & $-0,099$ & $-0,018$ & $-0,247$ & $-0,029$ & $-0,165$ & $-0,025$ & 0,131 \\
\hline \multicolumn{11}{|c|}{ Efectos directos } \\
\hline COND & 0,342 & 0,323 & $-0,026$ & $-0,098$ & 0,002 & 0,028 & 0,039 & $-0,112$ & 0,009 & $-0,098$ \\
\hline $\mathrm{CC}$ & & & 0,021 & $-0,101$ & 0,018 & 0,114 & 0,142 & $-0,082$ & $-0,066$ & 0,067 \\
\hline $\mathrm{CN}$ & & & $-0,148$ & $-0,099$ & $-0,018$ & $-0,247$ & $-0,029$ & $-0,165$ & $-0,025$ & 0,131 \\
\hline \multicolumn{11}{|c|}{ Efectos indirectos } \\
\hline COND & & & $-0,037$ & $-0,057$ & $-2,02 e-4$ & $-0,041$ & 0,039 & $-0,081$ & $-0,031$ & 0,065 \\
\hline
\end{tabular}

Etiquetas de variables: edad (EDAD), sexo (SEXO), ingresos netos del hogar mensuales (INGRES.), posición en el mercado (POSMERC.), número de prestaciones (PREST.), nivel de estudios (FORM.), eje ideológico (IZQDER.) escala de igualitarismo (IGUALIT), escala de criterios de conducta (CC.), escala de criterios de necesidad (CN.), escala de condicionalidad (COND.)

XAVIER GUIJARRO RUBINAT es doctor en Sociología por la Universidad Autónoma de Barcelona, donde ha colaborado con el Grupo de Sociología Analítica y Diseño Institucional (GSADI-UAB). Principales líneas de investigación: estado de bienestar, políticas públicas y formación de actitudes políticas. 